\title{
Management of Dentin Hypersensitivity
}

\author{
David G. Gillam ${ }^{1}$
}

Published online: 8 April 2015

(C) Springer International Publishing AG 2015

\begin{abstract}
A PubMed literature research was undertaken by the author using various MeSH terms: ("therapy"[Subheading] OR "therapy"[All Fields] OR "treatment"[All Fields] OR "therapeutics"[MeSH Terms] OR "therapeutics"[All Fields]) AND ("organization and administration"[MeSH Terms] OR ("organization"[All Fields] AND "administration"[All Fields]) OR "organization and administration"[All Fields] OR "management"[All Fields] OR "disease management" [MeSH Terms] OR ("disease"[All Fields] AND "management"[All Fields]) OR "disease management"[All Fields]) AND ("dentin sensitivity"[MeSH Terms] OR ("dentin"[All Fields] AND "sensitivity"[All Fields]) OR "dentin sensitivity"[All Fields] OR ("dentin"[All Fields] AND "hypersensitivity"[All Fields]) OR "dentin hypersensitivity"[All Fields]). This search strategy generated a large number of papers on the topic of dentin hypersensitivity (DH); however, there were limited data on management strategies that could be successfully implemented in clinical practice. Although there have been a number of treatment paradigms published in the literature, there is a need for simple pragmatic guidelines to be recommended to the clinician in order to successfully manage the condition in the clinical environment. Furthermore, despite
\end{abstract}

This article is part of the Topical Collection on Cariology

David G. Gillam

d.g.gillam@qmul.ac.uk

1 Centre for Adult Oral Health, Institute of Dentistry, Barts and the London School of Medicine and Dentistry, Queen Mary University, New Road, London E1 2AD, UK

URL: http://www.dentistry.qmul.ac.uk/ the published claims of clinical efficacy for both in-office and over-the-counter products there does not appear to be one ideal desensitizing agent than can be recommended to be used for the condition. The importance of educating both the clinician and the patient in the identification, prevention, and management of DH is paramount if the condition is to be successfully monitored and treated.

Keywords Dentin hypersensitivity $\cdot$ Clinical management strategies $\cdot$ Desensitizing products

\section{Introduction}

Dentin hypersensitivity (DH) is a recognized clinical condition that has been extensively reported on in the published literature particularly in the last 30 years, and yet there appears to be unresolved issues that still perplexed both the clinician and researcher. For example, overall prevalence figures from questionnaire studies rely on the patients' perception of DH which may overestimate the extent of the problem. This may be due, in part, to the patient's difficulty in determining the type of dental pain they may be experiencing at the time. According to Orchardson and Gillam [1], however, patients who complain of DH generally have lower prevalence values (15-30\%) following a clinical examination compared to those values recorded by questionnaire alone. A further question that has been recently addressed in the literature is the extent of the impact of DH on the quality of life of those who suffer with the condition $[2,3,4 \cdot 5]$. The question as to whether DH is a major problem for public health would however appear to suggest that $\mathrm{DH}$ is a relatively minor problem for the majority of the population as the discomfort is transient (episodic) in nature $[6,7]$. This may also be why some patients do not selftreat or report the problem when seeing a clinician $[8 \bullet \bullet$, 
although for at least $10 \%$ of the general population, DH may be considered to be a severe problem which may impact on their quality of life [9]. There are, however, a number of diagnostic challenges faced by the busy clinician when examining patients complaining of dental pain in general and more specifically with DH [7]; for example, (1) Is the prevalence of DH under or overestimated by clinicians in the practice environment? (2) Is the condition adequately diagnosed and successfully managed by clinicians in daily practice? (3) Is the clinician aware of the impact of DH on the quality of life (QOL) of their patients? (4) Is the condition adequately monitored by clinicians in daily practice? It would however appear that clinicians do not routinely screen/examine their patients for $\mathrm{DH}$ unless the patient prompts them [7]. There may also be a concern as to whether the clinician is confident in treating $\mathrm{DH}$ in daily practice particularly with the vast array of commercially available in-office and over-the-counter (OTC) that claim to be effective in reducing DH $[10,11]$. Furthermore, it may also be difficult for the clinician to effectively monitor DH in a busy dental practice and any guidelines that are produced to facilitate a treatment or management paradigm need to be simple and pragmatic in nature in order for the strategy to be implemented $[8 \bullet \cdot$. The aim of this review is, therefore, to update the clinician on the issues and challenges associated with the clinical management of dentin hypersensitivity and provide the clinician with simple guidelines on how to successfully manage the condition within the clinical environment.

\section{Terminology}

A number of other terms have been previously used in the published literature to describe dentin hypersensitivity (DH), for example, cervical dentin sensitivity (CDS), or cervical dentin hypersensitivity (CDH), or dentin sensitivity (DS), and more recently DHS. Although the term "dentin hypersensitivity" (DH) has been preferred in the published literature due in part to its historical significance [12], "dentin sensitivity" (DS) may be a more accurate term. DH has been defined as "pain derived from exposed dentin in response to chemical, thermal tactile, or osmotic stimuli which cannot be explained as arising from any other dental defect or disease" $[10,12]$. It is important therefore for the clinician to recognize that the definition of DH is essentially a diagnosis of exclusion. Although DH has been historically linked to individuals with relatively clean mouth, more recently, the term root sensitivity or root dentin sensitivity (RDS) or root dentin hypersensitivity $(\mathrm{RDH})$ has been used to describe tooth sensitivity arising from periodontal disease and its treatment [13-15]. Most published studies, however, do not distinguish these two groups when undertaking prevalence studies.

\section{Prevalence}

One of the problems when evaluating the evidence of the true prevalence of DH is that these figures vary depending on how the data was collected or where the studies took place (e.g. questionnaire (patient/clinician based), surveys, or clinical examination; general practice, university hospital, or consumer based), and these may range form 1 to $74 \%$ [15]. It is therefore apparent that a more universally accepted methodology (in terms of consistency and reproducibility) should be implemented by investigators when investigating the prevalence of $\mathrm{DH}$ in these disparate population groups. A recent review on the burden of DH by Cunha-Cruz and Wataha [16] based on the evidence of prevalence studies in the published literature would appear to suggest that the best overall estimate of the prevalence of DH in the population was $10 \%$.

\section{Mechanisms Involved in Dentin Hypersensitivity}

Although there have been a number of suggested mechanisms of the transmission of stimuli (e.g. cold, heat, sweet, etc.) across the dentin to the pulp, the currently held view is that the process is mediated through a hydrodynamic mechanism as proposed by Brännström and Åström [17]. However, not all stimulus transmission across the dentin can be explained by the hydrodynamic theory, and as such, there may be alternative mechanisms involved $[18,19]$. According to Narhi et al. [20], the intradental nerve fibers associated with $\mathrm{DH}$ are A nerve fibers (A- $\beta$ and A- $\delta$ ) in nature and probably activated by a hydrodynamic mechanism which may be dependent on whether the dentin tubules are open or blocked. Generally speaking, DH is differentiated from other associated tooth pain by A- $\delta$ fibers which are mainly stimulated by the application of a cold stimulus, producing sharp pain, compared to the stimulation of $\mathrm{C}$ fibers which produce dull aching pain $[21,22]$. The question of the role of pulpal inflammation (where chemically $\mathrm{C}$ fibers may be involved) in $\mathrm{DH}$, however, is still relatively unclear and somewhat controversial [23]. Furthermore, following more recent evidence in the published literature, the role of the odontoblast in $\mathrm{DH}$, often dismissed as an irrelevant mechanism in some text books, may also need to be reappraised [24].

\section{Etiology and Predisposing Features}

According to Gillam and Orchardson [15], a number of etiological and predisposing factors have been identified that have been implicated in the initiation of DH, for example, abrasion, abfraction, erosion, gingival recession, quality of the buccal bone, periodontal disease and its treatment, surgical and restorative procedures, and patient destructive habits. More 
recently, DH has also been considered to be a toothwear phenomenon characterized predominantly by erosion, which may expose the dentin surface and initiate the tooth wear lesions $[12,25]$. This concept has been supported by a number of studies that have reported on the prevalence (and risk factors) of DH associated with aspects of toothwear, for example, erosion, non-carious cervical lesions (NCCL), incisal/occlusal wear toothbrushing, and gingival recession [26, 27••, 28-30]. According to Dababneh et al. [23], there are two specific biological processes thought to be implicated in $\mathrm{DH}$, namely (1) lesion localization and (2) lesion initiation associated with the above-mentioned etiological factors. It is postulated that (1) the dentin has to be exposed as a result of the loss of enamel and/or soft tissue loss associated with gingival recession (including the loss of the cementum) (lesion localization). Secondly, once the dentin has been exposed, the patent dentin tubules will be open to the oral environment (lesion initiation) and as a consequence, any subsequent stimuli (e.g. cold) may initiate minute fluid movement within the dentin tubules, activating the mechanoreceptors in the inner third of the dentin.

One of the controversies that have arisen is the role of plaque in the etiology of $\mathrm{DH}$ which has divided opinion between investigators; for example, several investigators [31-34] have claimed that DH is as a result of "zealous" plaque control in a healthy mouth which affects mainly the buccal surfaces of the teeth, whereas other investigators such as Bissida et al. [35] have suggested that the condition may arise as a result of periodontal disease or poor oral hygiene due to acid metabolites from bacteria that subsequently open the dentin tubules. Wang et al. [36] however did not observe any relationship between plaque and DH whereas Addy et al. [34] showed a correlation between plaque score and DH. It may therefore be suggested that these two opposing philosophies may simply be different manifestations of the same clinical problem although there is no substantive evidence in the published literature to support this suggestion. More recently the "root sensitivity" (RS) was suggested by the European Federation of Periodontology [13] to describe tooth sensitivity associated with periodontal disease and/or periodontal therapy and by definition would consider RS to be a different condition compared to DH in so-called clean mouths.

\section{Clinical Features of DH}

According to Gillam et al. [8••], the teeth that have been identified to be commonly associated with DH are canines, premolars, and molars with the buccal aspect of the tooth more frequently exposed as a result of overzealous and/or incorrect toothbrushing in association with other etiological factors. It is important however to acknowledge that there may be different precipitating and predisposing factors associated with $\mathrm{DH}$, and these features should be carefully considered when deciding on a management strategy for treating DH. For example, according to Gillam et al. [8••], patients can be categorized as follows: patients (1) who have relatively healthy mouths and $\mathrm{DH}$ as a result of meticulous and perhaps overzealous oral hygiene, (2) who complain of DH as a result of periodontal disease and/or its treatment and may also have esthetic concerns relating to the loss of gingival tissue (gingival recession) and (3) who complain of DH as a result of toothwear problems. This management strategy may therefore help the clinician address the different presenting features associated with DH with a more tailored approach than simply following a non-specific generalized management strategy.

\section{Clinical Diagnosis of DH (Including Differential Diagnosis)}

According to Gillam [7], clinicians should therefore be made aware not only of the importance of identifying patients with DH but also of the relevance of a correct diagnosis that may exclude any confounding factors from other oro-facial pain conditions prior to the successful management of the condition. Several investigators, however, have reported on the difficulties that clinicians have faced when treating the condition, and it is clear that there is a need to recommend practical guidelines that may be implemented into a busy clinical practice $[8 \cdot \bullet, 11]$. It should also be acknowledged that the treatment and management of DH is generally considered difficult due to the highly subjective nature of the pain response and the variation of this response between individuals. Furthermore, it is essential that before any treatment is undertaken, a definitive diagnosis has been reached, and this involves as indicated by the definition of $\mathrm{DH}$ the exclusion of all other oral conditions with a similar presentation to that of $\mathrm{DH}$ (Fig. 1).

In order to determine a definitive diagnosis, it is important for the clinician to record a thorough history of the patient's complaint and this should include an assessment of the extent and severity of the problem. A number of methodological measures have been proposed to both qualify and quantify the pain associated with $\mathrm{DH}$, and these include both mechanical and thermal stimulation of the exposed dentin in order to elicit a response from the patient [37]. The so-called subjective response from the patient may also be recorded by a variety of accepted pain scales, for example, visual analog score scales (VAS), Schiff Cold Air Sensitivity Scale, verbal descriptors, and numerical scoring scales (e.g. 0-10) [37]. From the clinician's perspective, the use of an explorer probe and an air blast from a triple air syringe together with an indication of the degree of discomfort from the patient following the application of the stimulus during the clinical examination may be acceptable for both the identification of susceptible sites and 


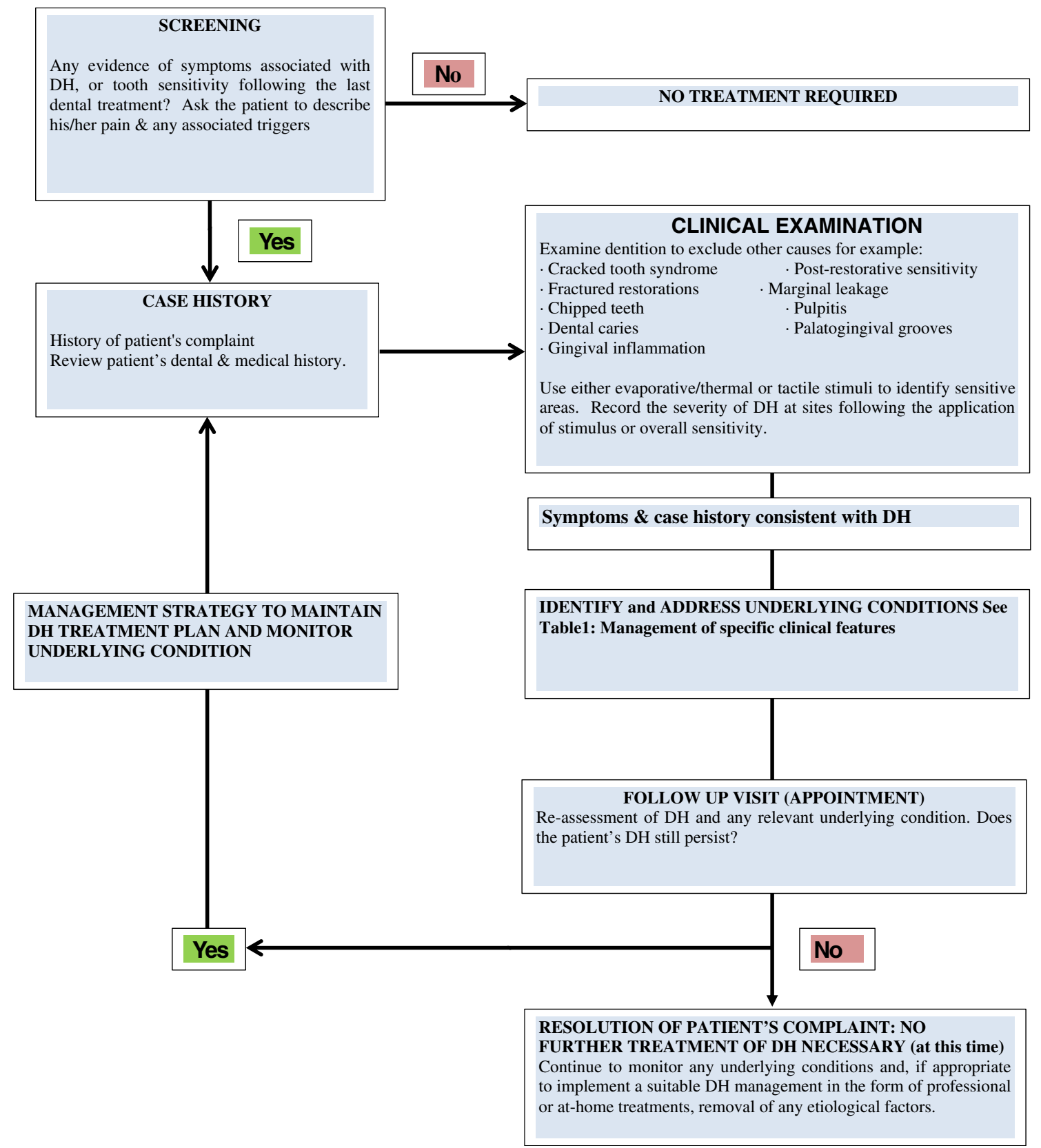

Fig. 1 Dentin Hypersensitivity Management Guidelines (Acknowledgement modified from Gillam et al. [8••]) "Reproduced from Dental Update (ISSN 0305-5000) by permission of George Warman Publications (UK) Ltd"

the severity of the pain response. When conducting clinical trials, however, more specialized devices are employed, for example, controlled pressure probes (Yeaple and Jay [Sensitivity Sensor] probes) [37-39], thermal probes, and standardized pain stimulation techniques using triple air syringe [37, 40]. The patient's subjective pain response following the application of these stimuli include the above-mentioned pain scales, and more recently, quality of life measures have also been included $[2,3,4 \cdot, 5]$. Several investigators however have criticized the methodology employed in the clinical trial environment due to the variability, lack of consistency, and reproducibility of the various stimuli used in the assessment [37, 40, 41]. Furthermore, the lack of patient/person-based outcomes in clinical trials that evaluate the efficacy of desensitizing products needs to be addressed [42].

\section{Clinical Management of Dentin Hypersensitivity}

There have been a number of treatment paradigms recommended in the literature relating to the management of $\mathrm{DH}$ $[1,10,43]$. One of the problems however with these paradigms 


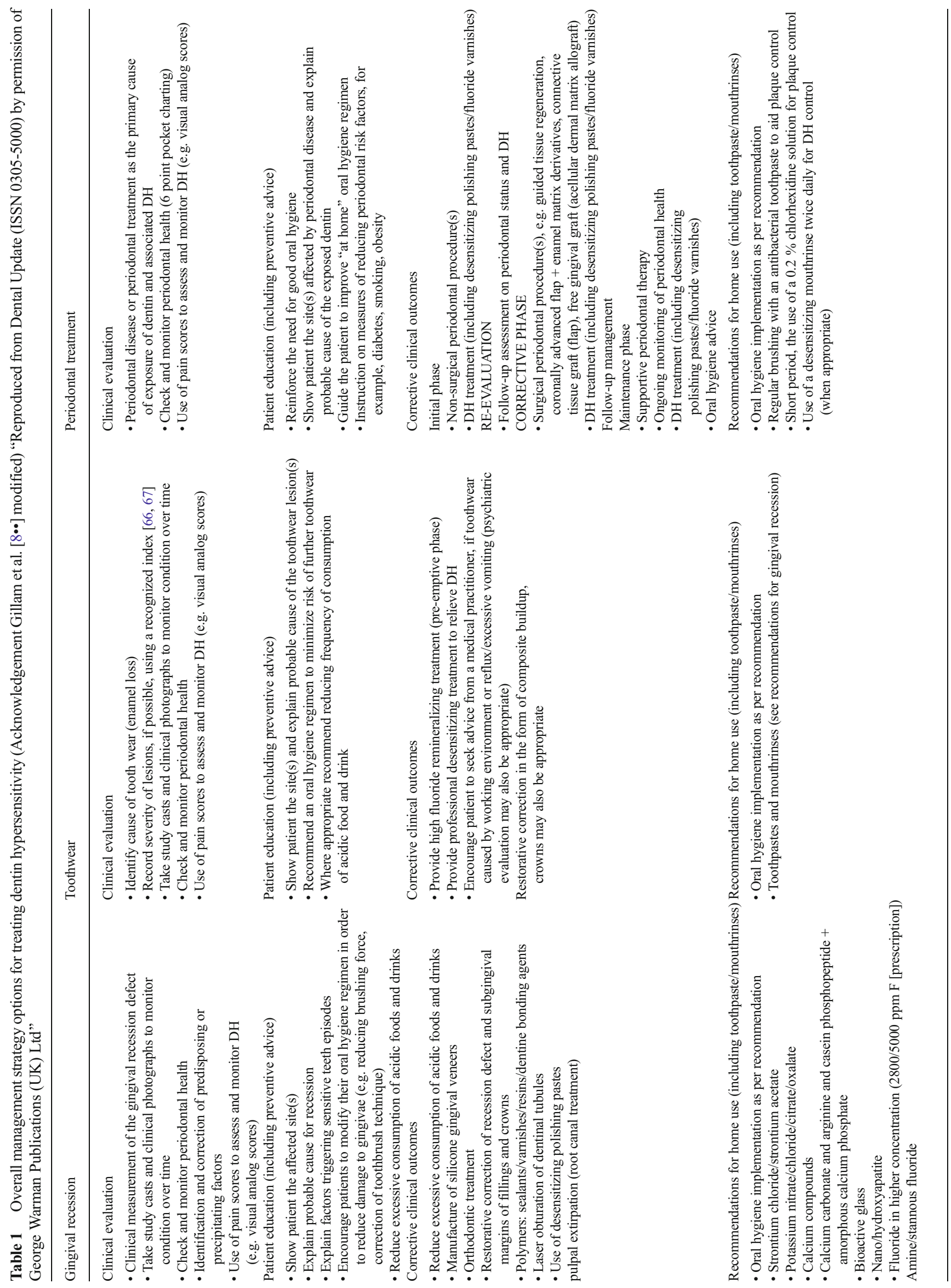


was that they were difficult to implement and effectively monitor DH over time in a busy dental practice, and as such, there is a need to produce guidelines that are relatively simple and pragmatic in nature in order for the strategy to be implemented (Gillam et al. [8••]). For example, a simple less invasive stepwise approach has been proposed by Orchardson and Gillam [1] which may be an appropriate strategy for managing $\mathrm{DH}$ depending of the extent and severity of DH. More recently, the UK Forum guidelines document on DH may also help clinicians to adopt a simplified management scheme which could be easier to implement into a clinical practice $[8 \bullet \bullet$. It is, however, important for the clinician to recognize that one of the key components from the UK guidelines document $[8 \bullet \bullet]$ was that no desensitizing product (OTC or professionally applied) can fully resolve the various presenting features of $\mathrm{DH}$, and therefore, it may be prudent for the clinician to utilize a range of products in order to resolve the patient's symptoms (Fig. 1, Table 1). The successful management of DH therefore not only involves the correct diagnosis of the condition by the clinician (which is essentially a diagnosis of exclusion) but also includes the importance of implementing prevention strategies that either eliminate or limit any further deterioration of DH by appropriate treatment choices, dietary advice, and monitoring of the condition $[1,8 \bullet \bullet]$.

The clinician has a range of both in-office (professionally applied) and over-the-counter (OTC) products which have been reported to be effective in reducing $\mathrm{DH}$ either through their tubular-occluding or nerve-desensitizing properties based on the principle of the hydrodynamic theory [1]. One of the problems, however, for the clinician is which of these in-office and OTC products would be effective both in the short and long term and while there have been a number of papers supporting the various claims of efficacy in reducing $\mathrm{DH}$, there does not appear to be one product that would be considered the gold standard for the treatment of DH. As indicated above, it is important for the clinician to have confidence in the ability of these products to successfully treat $\mathrm{DH}$; the evidence from the published literature would appear to suggest that this is not the case [11]. Furthermore, as indicated by Gillam et al. [8・•], the management of DH should not involve simply providing treatment without first removing any etiological factor associated with $\mathrm{DH}$ and educating the patient in reducing any future risk to the hard and soft tissues.

The clinician is somewhat reliant on the evidence in the published literature in regard to which product is more effective and while there is evidence of efficacy of these products, there are problems arising when comparing the results of the various products due to differences in study design, desensitizing products, duration, assessment methodology, etc. For example, there have been a number of published papers on OTC products containing stannous, strontium, potassium, arginine, oxalate, and hydroxyapatite ingredients and inoffice products and procedures (varnishes, sealants, glass ionomer cements, lasers) that would suggest a degree of efficacy when used to treat DH) $[1,44-51]$. However, a number of systematic reviews appear to give equivocal results, some positive and a number of negative reviews [52-63, 64•]. Although the consensus from these reviews appears to be that there is evidence for the various claims of efficacy for most of these in-office and OTC products, nevertheless the entire body of clinical research literature is far from being unequivocal in pronouncing one superior strategy $[8 \bullet \bullet, 64 \bullet, 65]$.

\section{Conclusions}

Recent proposals by a UK Expert Forum on DH [8••] would appear to provide practical, evidence-based guidance on the management of $\mathrm{DH}$ for the diagnosis, monitoring, prevention, and treatment of specific presenting features of patients with DH. It is also evident from the published literature that a one strategy management approach cannot fully resolve the problem for all patients with DH. The importance of educating both the clinician and the patient in the identification, prevention, and management of $\mathrm{DH}$ is paramount if the condition is to be successfully monitored and treated.

\section{Compliance with Ethics Guidelines}

Conflict of Interest David G. Gillam reports grants from Industrial Funding to conduct laboratory studies for Ph.D. postgraduates in conjunction with colleagues, grants from Industrial Funding to cover expenses of mailing questionnaires on the perceptions of UK dentists and hygienists on the identification and management of dentin hypersensitivity, and personal fees from the Consensus Meeting on UK Guidelines 2013. This group was sponsored by a Consumer Health Company. Grants from internal and external awards for the further development of a novel desensitizing toothpaste and mouthrinse, together with personal fees from speaking at Meetings and Conferences on behalf of Consumer Health Care Companies to lecture or chair (subject: dentin hypersensitivity), were outside the submitted work. In addition, Dr. Gillam has a patent WO2011/161422 issued to Hill R, Brauer D, Gillam DG, Karpukhina N, Bushby A, and Mneimne, M (2011) and a patent GB2499317 issued to Hill RH, Collings A, Baynes I and Gillam D (2014).

Human and Animal Rights and Informed Consent This article does not contain any studies with human or animal subjects performed by any of the authors.

\section{References}

Papers of particular interest, published recently, have been highlighted as:

- Of importance

•• Of major importance

1. Orchardson R, Gillam DG. Managing dentin hypersensitivity. J Am Dent Assoc. 2006;137(7):990-8. 
2. Bekes K, John MT, Schaller H-G, Hirsch C. Oral health-related quality of life in patients seeking care for dentin hypersensitivity. J Oral Rehabil. 2009;36(1):45-51.

3. Bioko OV, Baker SR, Gibson BJ, Locker D, Sufi F, Barlow APS, et al. Construction and validation of the quality of life measure for dentine hypersensitivity (DHEQ). J Clin Periodontol. 2010;37: 973-80.

4. Bekes K, Hirsch C. What is known about the influence of dentine hypersensitivity on oral health-related quality of life. Clin Oral Investig. 2013;17(supplement 1):S45-51

The article addresses the importance of recognizing the potential impact of the pain associated with dentin hypersensitivity on the individual's Quality of Life.

5. Gibson B, Boiko OV, Baker S, Robinson PG, Barlow A, Player T, et al. The everyday impact of dentin sensitivity: personal and functional aspects. Soc Sci Dent. 2010;1(1):11-20.

6. Rees JS, Addy M. A cross-sectional study of buccal cervical sensitivity in UK general dental practice and a summary review of prevalence studies. Int J Dent Hyg. 2004;2(2):64-9.

7. Gillam DG. Current diagnosis of dentin hypersensitivity in the dental office: an overview. Clin Oral Investig. 2013;17(supplement 1): S21-9.

8.• Gillam DG, Chesters RK Attrill DC, Brunton P, Slater M, Strand P, Whelton H, et al. Dentine hypersensitivity — guidelines for the management of a common oral health problem. Dent Updat. 2013;40: $514-24$

Provides the clinician with simple guidelines for the management of dentin hypersensitivity based on specific presenting clinical features.

9. Gillam DG, Bulman JS, Eijkman MAJ, Newman HN. Dentists' perception of dentin hypersensitivity and knowledge of its treatment. J Oral Rehabil. 2002;29:219-25

10. Canadian Advisory Board on Dentin Hypersensitivity. Consensusbased recommendations for the diagnosis and management of dentin hypersensitivity. J Can Dent Assoc. 2003;69(4):221-6.

11. Cunha-Cruz J, Wataha JC, Zhou L, Manning W, Trantow M, Bettendorf MM, et al. Treating dentin hypersensitivity: therapeutic choices made by dentists of the northwest PRECEDENT network. $\mathrm{J}$ Am Dent Assoc. 2010;141(9):1097-105.

12. Addy M. Dentin hypersensitivity: definition, prevalence distribution and etiology. In: Addy M, Embery G, Edgar WM, Orchardson R, editors. Tooth wear and sensitivity. London: Martin Dunitz; 2000. p. 239-48.

13. Sanz M, Addy M. Group D summary. J Clin Periodontol. 2002;29(supplement 3):195-6.

14. von Troil B, Needleman I, Sanz M. A systematic review of the prevalence of root sensitivity following periodontal therapy. J Clin Periodontol. 2002;29(3):173-7.

15. Gillam D, Orchardson R. Advances in the treatment of root dentin sensitivity: mechanisms and treatment principles. Endod Top. 2006;13:13-33.

16. Cunha-Cruz J, Wataha JC. The burden of dentine hypersensitivity. In: Robinson PG, editor. Dentine hypersensitivity: developing a person-centred approach to oral health. Oxford: Academic Press, Elsevier B.V; 2014. p. 34-44.

17. Brännström $\mathrm{M}$, Åström A. The hydrodynamics of the dentin; its possible relationship to dentinal pain. Int Dent J. 1972;22(2):219 27.

18. Naylor MN. A thermo-electric tooth stimulator. Br Dent J. 1961;110:228-30

19. Gillam DG. Mechanisms of stimulus transmission across dentin - a review. J West Soc Periodontol Periodontal Abstr. 1995;43(2):5365. Review

20. Narhi M, Kontturi-Narhi V, Hirvonen T, Ngassapa D. Neurophysiological mechanisms of dentin hypersensitivity. Proc Finn Dent Soc. 1992;88 Suppl 1:15-22.
21. Ngassapa D. Correlation of clinical pain symptoms with histopathological changes of the dental pulp: a review. East Afr Med J. 1996;73:779-81.

22. Abd-Elmeguid A, Yu DC. Dental pulp neurophysiology: part 1. Clinical and diagnostic implications. J Can Dent Assoc. 2009;75: 55-9.

23. Dababneh RH, Khouri AT, Addy M. Dentine hypersensitivity - an enigma? A review of terminology, mechanisms, aetiology and management. Br Dent J. 1999;187:606-11.

24. Markowitz K, Pashley DH. Discovering new treatments for sensitive teeth: the long path from biology to therapy. J Oral Rehabil. 2008;35(4):300-15.

25. Addy M. Toothbrushing, tooth wear and dentine hypersensitivityare they associated? Int Dent J. 2005;65(4):261-7.

26. Que K, Guo B, Jia Z, Chen Z, Yang J, Gao PA. Cross-sectional study: non-carious cervical lesions, cervical dentine hypersensitivity and related risk factors. J Oral Rehabil. 2013;40(1):24-32.

27.• West NX, Sanz M, Lussi A, Bartlett D, Bouchard P, Bourgeois D. Prevalence of dentine hypersensitivity and study of associated factors: a European population-based cross sectional study. J Dent. 2013;41:841-51

Prevalence data that demonstrates a strong relationship between dentin hypersensitivity and erosive toothwear, which is important to recognise for patient preventive therapies and the management of pain associated with dentin hypersensitivity.

28. Bartlett DW, Lussi A, West NX, Bouchard P, Sanz M, Bourgeois D. Prevalence of tooth wear on buccal and lingual surfaces and possible risk factors in young European adults. J Dent. 2013;41:100713.

29. Naidu GM, Ram KC, Sirisha NR, Sree YS, Kopuri RK, Satti NR, et al. Prevalence of dentin hypersensitivity and related factors among adult patients visiting a dental school in Andhra Pradesh, southern India. J Clin Diagn Res. 2014;8(9):ZC48-51.

30. Olley R, Moazze, R, Bartlett D. The relationship between incisal/ occlusal wear, dentine hypersensitivity and time after the last acid exposure in vivo. J Dent. 2014;42. doi:10.1016/j.jdent.2014.11. 002 .

31. GrafH, Galass Morbidity R. Prevalence and intraoral distribution of hypersensitivity teeth. J Dent Res. 1977;53(abstract 479):A162.

32. Flynn J, Galloway R, Orchardson R. The incidence of 'hypersensitive' teeth in the West of Scotland. J Dent. 1985;13(3):230-6.

33. Addy M, Mostafa P, Newcombe RG. Dentine hypersensitivity: the distribution of recession, sensitivity and plaque. J Dent. 1987;15(6): 242-8.

34. Addy M, Mostafa P, Absi EG, Adams D. Cervical dentin hypersensitivity. Etiology and management with particular reference to dentifrices. In: Rowe NH, editor. Proceedings of symposium on hypersensitive dentin — origin and management. University of Michigan; 1985. pp 147-167.

35. Bissada NF. Symptomatology and clinical features of hypersensitive teeth. Arch Oral Biol. 1994;39(Suppl):31S-2S.

36. Wang HL, Yeh CT, Smith F, Burgett FG, Richards P, Shyr Y, et al. Evaluation of ferric oxalate as an agent for use during surgery to prevent post-operative root hypersensitivity. J Periodontol. 1993;64(11):1040-4.

37. Gillam DG, Orchardson R, Narhi MVO, Kontturi-Narhi V. Present and future methods for the evaluation of pain associated with dentine hypersensitivity. In: Addy M, Embery G, Edgar WM, Orchardson R, editors. Tooth wear and sensitivity. London: Martin Dunitz; 2000. p. 283-98.

38. Sowinski JA, Kakar A, Kakar K. Clinical evaluation of the Jay Sensitivity Sensor Probe: a new microprocessor-controlled instrument to evaluate dentin hypersensitivity. Am J Dent. 2013;26(Spec No B):5B-12B

39. Kakar A, Kakar K. Measurement of dentin hypersensitivity with the Jay Sensitivity Sensor Probe and the Yeaple probe to compare relief 
from dentin hypersensitivity by dentifrices. Am J Dent. 2013;26(Spec No B):21B-8B.

40. Ide M, Wilson RF, Ashley FP. The reproducibility of methods of assessment for cervical dentine hypersensitivity. J Clin Periodontol. 2001;28(1):16-22.

41. Gillam DG, Newman HN. Assessment of pain in cervical dentinal sensitivity studies. A review. J Clin Periodontol. 1993;20(6):38394.

42. Robbins DA, Curro FA, Mattison J. Person-centric clinical trials: ethical challenges in recruitment and data transparency for improved outcomes. J Clin Pharmacol. 2014;54(9):1072-7.

43. Addy M, Urquhart E. Dentine hypersensitivity: its prevalence, aetiology and clinical management. Dent Updat. 1992;19(10): 407-8. 10 .

44. Cummins D. Recent advances in dentin hypersensitivity: clinically proven treatments for instant and lasting sensitivity relief. Am J Dent. 2010;23:3A-13A.

45. Shetty S, Kohad R, Yeltiwar R. Hydroxyapatite as an in-office agent for tooth hypersensitivity: a clinical and scanning electron microscopic study. J Periodontol. 2010;81(12):1781-9.

46. Yilmaz HG, Kurtulmus-Yilmaz S, Cengiz E, Bayindir H, Aykac Y. Clinical evaluation of Er, Cr:YSGG and GaAlAs laser therapy for treating dentine hypersensitivity: a randomized controlled clinical trial. J Dent. 2011;39(3):249-54.

47. Yuan P, Shen X, Liu J, Hou Y, Zhu M, et al. Effects of dentifrice containing hydroxyapatite on dentinal tubule occlusion and hexavalent chromium cations sorption: a preliminary study. PLoS ONE. 2012;7(12):e45283. doi:10.1371/journal.pone.0045283.

48. Rajesh KS, Hedge S, Arun Kumar MS, Shetty DG. Evaluation of the efficacy of a $5 \%$ calcium sodium phosphosilicate $\left(\right.$ Novamin ${ }^{\mathbb{R}}$ ) containing dentifrice for the relief of dentinal hypersensitivity: a clinical study. Indian J Dent Res. 2012;23:363-7.

49. He T, Barker ML, Biesbrock A, Sharma N. A randomized controlled clinical trial to assess the desensitizing effect of a stannous fluoride dentifrice. Am J Dent. 2014;27(2):106-10.

50. He T, Barker ML, Biesbrock AR, Miner M, Qaqish J, Sharma N. A clinical study to assess the effect of a stabilized stannous fluoride dentifrice on hypersensitivity relative to a marketed sodium fluoride/triclosan control. J Clin Dent. 2014;25(2):13-8.

51. Sharma D, McGuire JA, Amini P. Randomized trial of the clinical efficacy of a potassium oxalate-containing mouthrinse in rapid relief of dentin sensitivity. J Clin Dent. 2013;24(2):62-7.

52. Jackson RJ. Potential treatment modalities for dentine hypersensitivity: home use products. In: Addy M, Embery G, Edgar WM, Orchardson R, editors. Tooth wear and sensitivity. London: Martin Dunitz; 2000. p. 328-38.
53. Orchardson R, Gillam DG. The efficacy of potassium salts as agents for treating dentine hypersensitivity. J Orofac Pain. 2000;14(1):9 19.

54. Poulsen S, Errboe M, Lescay Mevil Y, Glenny A-M. Potassium containing toothpastes for dentine hypersensitivity. Cochrane Database of Syst Rev. 2006;3CD001476.

55. Cunha-Cruz J, Stout JR, Heaton LJ, Wataha JC, Northwest PREC EDENT. Dentin hypersensitivity and oxalates: a systematic review. J Dent Res. 2011;90(3):304-10.

56. Karim BFA, Gillam DG. The efficacy of strontium and potassium toothpastes in treating dentine hypersensitivity: a systematic review. Int J Dent. 2013;2013:13 pages.573258

57. Da Rosa WL, Lund RG, Piva E, da Silva AF. The effectiveness of current dentin desensitizing agents used to treat dental hypersensitivity: a systematic review. Quintessence Int. 2013;44(7):535-46.

58. Yan B, Yi J, Li Y, Chen Y, Shi Z. Arginine-containing toothpastes for dentin hypersensitivity: systematic review and meta-analysis. Quintessence Int. 2013;44(9):709-23. doi:10.3290/j.qi.a30177.

59. He S, Wang Y, Li X, Hu D. Effectiveness of laser therapy and topical desensitising agents in treating dentine hypersensitivity: a systematic review. J Oral Rehabil. 2011;38(5):348-58.

60. Sgolastra F, Petrucci A, Severino M, Gatto R, Monaco A. Lasers for the treatment of dentin hypersensitivity: a meta-analysis. J Dent Res. 2013;92(6):492-9.

61. Lin PY, Cheng YW, Chu CY, Chien KL, Lin CP, Tu YK. In-office treatment for dentin hypersensitivity: a systematic review and network meta-analysis. J Clin Periodontol. 2013;40:53-64.

62. Li R, Tang XJ, Li YH, Wang Y, Chen J, Wang QH, et al. Argininecontaining desensitizing toothpaste for dentine hypersensitivity: a meta-analysis. Chin J Evid Based Med. 2011;11(5):570-5.

63. Sharif MO, Iram S, Brunton PA. Effectiveness of argininecontaining toothpastes in treating dentine hypersensitivity: a systematic review. J Dent. 2013;41(6):483-92.

64. West NX, Davies M. Management of dentine hypersensitivity: efficacy of professionally and self-administered agents. J Clin Periodontol. 2014. doi:10.1111/jcpe. 12336

Good overview of the evidence supporting the efficacy of both professionally and self-administered desensitising products designed to treat dentin hypersensitivity.

65. Shiau HJ. Dentin hypersensitivity. J Evid Based Dent Pract. 2012;S1:220-8.

66. Smith B, Knight J. An index for measuring the wear of teeth. Br Dent J. 1984;156:435-8.

67. Bartlett D, Ganss C, Lussi A. Basic Erosive Wear Examination (BEWE): a new scoring system for scientific and clinical needs. Clin Oral Investig. 2008;12 Suppl 1:65-8. 